\title{
Regulation of miR-101/miR-199a-3p by the epithelial sodium channel during embryo implantation: involvement of CREB phosphorylation
}

\author{
Xiao Sun*, Ye Chun Ruan*, Jinghui Guo, Hui Chen, Lai Ling Tsang, Xiaohu Zhang, \\ Xiaohua Jiang and Hsiao Chang Chan \\ Epithelial Cell Biology Research Center, Key Laboratory for Regenerative Medicine of Ministry of Education of China, \\ Faculty of Medicine, School of Biomedical Sciences, The Chinese University of Hong Kong, Shatin, Hong Kong
}

Correspondence should be addressed to H C Chan; Email: hsiaocchan@Cuhk.edu.hk

${ }^{*}(\mathrm{X}$ Sun and Y C Ruan contributed equally to this work)

\begin{abstract}
In our previous study, we have demonstrated that the epithelial sodium channel (ENaC) mediates the embryo-derived signals leading to the activation of CREB and upregulation of cyclooxygenase type 2 (COX2) required for embryo implantation. This study aims to investigate whether microRNAs (miRNAs) are involved in the ENaC-induced upregulation of COX2 during embryo implantation. The results show that the levels of miR-101 and miR-199a-3p, two COX2 targeting miRNAs, are reduced by ENaC activation, and increased by $\mathrm{ENaC}$ inhibition or knock-down of $\mathrm{ENaC}$ subunit $(\mathrm{ENaC} \alpha)$ in human endometrial surface epithelial (HES) cells or in mouse uteri during implantation. Phosphorylation of CREB is induced by the activation of ENaC, and blocked by ENaC inhibition or knockdown in HES cells. Knockdown of ENaC $\alpha$ or CREB in HES cells or in mouse uterus in vivo results in increases in miR-101 and miR-199a-3p, accompanied with decreases in COX2 protein levels and reduction in implantation rate. The downregulation of COX2 caused by knockdown of ENaC or CREB can be recovered by the inhibitors of miR-101 or miR-199a-3p in HES cells. These results reveal a novel molecular mechanism modulating COX2 expression during embryo implantation via ENaC-dependent CREB activation and COX2-targeting miRNAs.

Reproduction (2014) 148 559-568
\end{abstract}

\section{Introduction}

The implantation of the blastocyst into the uterus is one of the most critical steps in human reproduction. Implantation failure is associated with $\sim 75 \%$ pregnancy loss in humans (Wilcox et al. 1988, Norwitz et al. 2001), and aberrant embryo implantation can lead to adverse consequences during the later course of pregnancy such as placental insufficiency and preterm-labor in humans (Cha et al. 2012). Although a variety of signaling molecules associated with implantation have been identified (see reviews by Cha et al. (2012), Koot et al. (2012) and Ruan et al. (2014)), the mechanisms underlying implantation remain largely unclear.

Cyclooxygenase type 2 (COX2), a rate-limiting enzyme for prostaglandins (PGs) production in multiple organs and tissues (Ruan et al. 2011), is abundantly expressed in the endometrium during implantation period in mice and humans (Lim et al. 1997, Critchley et al. 1999, Marions \& Danielsson 1999) and known to be a key factor for embryo implantation. COX2knockout mice show multiple problems in female reproduction, including implantation failure (Lim et al.
1997, 1999, Matsumoto et al. 2002). In humans, exposure to non-steroidal anti-inflammatory drugs (NSAIDs), which inhibit cyclooxygenases, during pregnancy especially at the time of conception is associated with over $80 \%$ increased risk of miscarriage ( $\mathrm{Li}$ et al. 2003). COX2-derived prostaglandin $E_{2}\left(P E_{2}\right)$ is considered as one of the most important signaling molecules for the initiation and progression of embryo implantation (Lim et al. 1997). Women in IVF trials with repeated implantation failure are reported to have defective endometrial prostaglandin synthesis (Achache et al. 2010). The expression of COX2 can be induced by various factors, among which, CREB is known to be a key transcription factor that binds to COX2 promoter region for its upregulation (Miller et al. 1998, Tsatsanis et al. 2006, Pham et al. 2008). However, the role of CREB in the regulation of COX2 in the endometrium during embryo implantation is not well studied.

COX2 expression can also be regulated by microRNAs (miRNAs), a family of short (18-25nt) non-coding RNAs (Chakrabarty et al. 2007, Akhtar \& Haqqi 2012). In general, miRNAs are spatiotemporally expressed and, 
by binding to 3' UTRs of their targeting mRNAs to induce mRNA degradation or translation repression, they are able to fine tune the expression of a series of their target genes and influence multiple physiological and pathological processes (He \& Hannon 2004, Du \& Zamore 2005, Ouellet et al. 2006, Nilsen 2007). In fact, miRNAs are emerging as a group of gene-expression modulators critically involved in embryo implantation (Chakrabarty et al. 2007, Hu et al. 2008, Nagaraja et al. 2008, Revel et al. 2011). They have been shown to exhibit dynamic temporal and spatial expression in both the uterus and the blastocyst during implantation (Hossain et al. 2012, Su et al. 2014). Interestingly, two miRNAs predicted to target COX2, miR-101a and miR-199a-3p, have also been reported to be spatiotemporally expressed in the uterus which coincides with the expression of COX2 during implantation in mice, suggesting the potential role of these miRNAs in the process (Chakrabarty et al. 2007). However, how these two miRNAs are regulated during embryo implantation remains unknown. Interestingly, CREB has recently been reported to have the capacity of repressing miR-101 transcription in embryonic fibroblasts (Kottakis et al. 2011).

The amiloride-sensitive epithelial sodium channel $(\mathrm{ENaC})$ is expressed in various epithelia, including endometrial epithelium (Chan et al. 2002, Yang et al. 2004, Ruan et al. 2014), which is essential to sodium and water homeostasis in the body (Hummler et al. 1996, Salker 2010). ENaC has been shown to exhibit cyclic expression pattern during the estrous cycle with a high expression level observed at diestrus and peri-implantation period (Chan et al. 2002, Yang et al. 2004). Like its well-known role in other epithelia, $\mathrm{ENaC}$ has been demonstrated to be involved in uterine fluid absorption, which is suggested to be responsible for the reduced uterine fluid volume during embryo implantation (Chan et al. 2000a,b, 2001, Tsang et al. 2001, Ruan et al. 2014). It has been recently recognized that $\mathrm{ENaC}$ plays an essential role in the initiation of embryo implantation in addition to regulation of uterine fluid volume (Ruan et al. 2012). ENaC is shown to be activated by an embryo-released protease, which results in a sequence of events in the endometrial epithelial cells, including membrane depolarization, activation of voltagesensitive $\mathrm{Ca}^{2+}$ channel, phosphorylation/activation of CREB, upregulation of COX2, and $\mathrm{PGE}_{2}$ release, leading to stromal cell decidualization (Ruan et al. 2012), a prerequisite for successful embryo implantation (Cha et al. 2012). Inhibition or knockdown of $\mathrm{ENaC}$ in mice leads to disrupted decidualization and implantation failure, indicating the essential role of $\mathrm{ENaC}$ in embryo implantation (Ruan et al. 2012). The importance of $\mathrm{ENaC}$ in human embryo implantation is also highlighted by the observation on clinical samples showing lowered endometrial $\mathrm{ENaC}$ expression levels in women with failed pregnancy during their IVF trials compared with women with successful pregnancy (Ruan et al. 2012).
The observed phosphorylation of CREB upon activation of $\mathrm{ENaC}$ and the reported capacity of CREB in repressing one of the COX2-targeting miRNAs prompted us to hypothesize that in addition to directly inducing COX2 transcription, the ENaC-dependent CREB activation may lead to the suppression of miR-101 and miR-199a-3p, which may in turn augment COX2 upregulation during embryo implantation. This study, using mouse and human endometrial epithelial cells and a mouse in vivo implantation model along with gene knockdown assays, demonstrates that $\mathrm{ENaC}$ is involved in the regulation of the two COX2-targeting miRNAs, miR-101 and miR-199a-3p, through CREB phosphorylation during embryo implantation.

\section{Materials and methods}

\section{Materials}

Trypsin (catalog \#93611), amiloride (catalog \#A7410), and nifedipine (catalog \#N-7634) were purchased from SigmaAldrich. siGENOME siRNA-SMARTpool targeting mouse Creb1 (catalog \#M-040959-01) and siGENOME non-targeting siRNA pool (catalog \#D-001206-14) were purchased from Thermo Scientific, Waltham, MA, USA. Stealth siRNA (AAA GCA AAC UGC CAG UAC AUC AUG $C$ and GCA UGA UGU ACU GGC AGU UUG CUU U) targeting mouse ENaC $\alpha$, Stealth RNAi Negative Control Lo GC Duplex, Silencer siRNAs-targeting human CREB1 (catalog \#109994), Silencer negative control siRNAs (catalog \#AM4611), miR-101 inhibitor (ID-MH11414), miR-199a-3p inhibitor (ID-AM11779), mirVana miRNA Inhibitor Negative Control \#1 (catalog \#4464077), and Lipofectamine 2000 transfection reagent (catalog \#11668) were purchased from Invitrogen Life Technologies.

\section{Mice and intrauterine injection}

Female imprinting control region (ICR) mice were obtained from the Laboratory Animal Service Centre of the Chinese University of Hong Kong. All animal experiments were carried out in accordance with guidelines on animal experimentation, and approval by the Animal Ethics Committee of the Chinese University of Hong Kong. The day a vaginal plug was found after mating was designated as day 1 after mating. Surgery under general anesthesia was performed on day 3. Dorsal midline skin incision was made and followed by two small incisions into the muscle wall near each ovary to expose the uterine-oviduct connecting region. siRNAs (20 pmol) was mixed with Lipofectamine $2000(1 \mu \mathrm{l})$ in Opti-MEM $(20 \mu \mathrm{l}$, catalog \#31985062, Invitrogen Life Technologies) for $30 \mathrm{~min}$ to $1 \mathrm{~h}$ at room temperature before being injected into the lumen of each uterine horn at the uterotubal junction. siRNA-NC and siRNA-CREB were each injected into a separate uterine horn in each mouse. Afterwards, wounds were closed by suture and the mice were placed on a $37^{\circ} \mathrm{C}$ warmer till wake-up from the anesthesia. Temgesic was given to the mice by s.c. injection 12,24 , and $48 \mathrm{~h}$ after surgery to reduce the pain. The mice were closely monitored for 3 consecutive days after the surgery. On day 7 , the mice were killed by anesthetic overdose 
or $\mathrm{CO}_{2}$ asphyxiation and the implanted embryo numbers were counted.

\section{Cell culture}

Mouse primary endometrial epithelial cells (mEECs) were isolated and cultured as previously described (Chan et al. $2000 a, b)$. Briefly, the uteri were collected from six to eight immature ICR mice (24 days of age), sliced longitudinally, and incubated in PBS with $6.5 \mathrm{mg} / \mathrm{ml}$ trypsin and $25 \mathrm{mg} / \mathrm{ml}$ pancreatin on ice for $60 \mathrm{~min}$ and then $45 \mathrm{~min}$ at room temperature. Afterwards, the uteri were transferred to fresh PBS and gently shaken for $30 \mathrm{~s}$ to release the epithelial cells. The isolated cells were cultured in DMEM/F-12 with $10 \%(\mathrm{v} / \mathrm{v})$ fetal bovine serum (FBS) and $1 \%$ penicillin-streptomycin ( $/ \mathrm{v}$ ) in $5 \%$ $\mathrm{CO}_{2}$ incubator at $37{ }^{\circ} \mathrm{C}$ till confluence before other experiments. The human endometrial surface epithelial (HES) cell line was a gift from Douglas A Kniss from the Laboratory of Perinatal Research at the Ohio State University (Kniss et al. 1997). The HES cells were cultured in DMEM supplemented with 10\% FBS $(\mathrm{v} / \mathrm{v})$ and $1 \%$ penicillin-streptomycin $(\mathrm{v} / \mathrm{v})$ in $5 \% \mathrm{CO}_{2}$ incubators at $37^{\circ} \mathrm{C}$.

\section{Gene knockdown}

Lenti-virus (LV3) packaged shRNAs-targeting human ENaC $\alpha$ (5'-GTG GCT GTG CCT ACA TCT TCT- $3^{\prime}$ ) or scrambled noncoding shRNAs ( $5^{\prime}$-TTC TCC GAA CGT GTC ACG TTT- $\left.3^{\prime}\right)$ were purchased from GenePharma (Shanghai, China). The viruses $\left(2 \times 10^{7} \mathrm{TU} / \mathrm{ml}\right)$ were transduced into HES cells with Polybrene $(5 \mu \mathrm{g} / \mathrm{ml})$. The cells were cultured in the presence of puromycin $(5 \mu \mathrm{g} / \mathrm{ml})$ for three passages to select stable clones before other experiments. The siRNAs-targeting human CREB1, non-targeting siRNAs, miR-101 inhibitor, miR-199a-3p inhibitor, or miRNA inhibitor negative control $(100 \mathrm{nM})$ was transfected with Lipofectamine 2000 transfection reagent into HES cells. Forty-eight hours after transfection, the cells were collected for further studies.

\section{Intracellular calcium imaging}

The HES cells grown on cover slips were washed and loaded with Fura-2 (3 $\mu \mathrm{M}$, Invitrogen Life Technologies) at $37^{\circ} \mathrm{C}$ for $30 \mathrm{~min}$ in Margo solution (in mM: $\mathrm{NaCl} 130, \mathrm{KCl} 5, \mathrm{CaCl}_{2} 2.5, \mathrm{MgCl}_{2} 1$, HEPES 20, and glucose 10). Fluorescence excited at 340 and $380 \mathrm{~nm}$ was monitored by an inverted microscope (Nikon Ti-U).

\section{$P G E_{2}$ ELISA}

The HES cells were grown in 24-well plates till $80 \%$ confluence before 1\% FBS DMEM was used for $8 \mathrm{~h}$ to synchronize the cells. FBS-free DMEM was used for all the treatments and collected for the EIA Kit (catalog \#514010, Cayman Chemical, Ann Arbor, MI, USA).

\section{Western blotting analysis}

The cells or tissues were lysed in radioimmunoprecipitation assay (RIPA) lysis buffer $(\mathrm{NaCl} 150 \mathrm{mM}$, Tris-Cl $(\mathrm{pH}=8.0)$
$50 \mathrm{mM}, \mathrm{NP}-401 \% \mathrm{v} / \mathrm{v}$, sodium deoxycholate $0.5 \% \mathrm{w} / \mathrm{v}$, and SDS $0.1 \% \mathrm{w} / \mathrm{v}$ ) with protease inhibitor cocktail (catalog \#88266, Thermo Scientific, Waltham, MA, USA) and $1 \mathrm{mM}$ phenylmethylsulfonyl fluoride. The lysates were analyzed by SDS-PAGE followed by probing antibodies. Antibodies against ENaC $\alpha$ (1:500, catalog \#sc-22239, Santa Cruz Biotechnology, Dallas, TX, USA), ENaC $\gamma(1: 1000$, catalog \#ab3468, Abcam, Cambridge, UK), COX2 (1:500, catalog \#160106, Cayman Chemical), CREB (1:500, catalog \#9197, Cell Signaling Technology, Danvers, MA, USA), and P-CREB (1:500, catalog \#9198, Cell Signaling Technology) were used. For loading controls, antibodies against $\beta$-tubulin (catalog \#sc-9104, Santa Cruz Biotechnology) and GAPDH (catalog \#sc-47724, Santa Cruz Biotechnology) were used. The signal was detected with HRP-conjugated antibodies (catalog \#170-6515, 170-6516, Bio-Rad and catalog \#sc-2020, Santa Cruz Biotechnology) and visualized by ECL detection reagents (catalog \#RPN2106, RPN2232, GE Healthcare, Little Chalfont, Buckinghamshire, UK). Densitometry of western blottings was performed using the freely available ImageJ Software.

\section{RNA extraction and real-time PCR}

The cells were lysed in TRIzol reagent (Invitrogen Life Technologies) according to manufacturer's instructions. Realtime PCR assays were carried out in triplicate on an Applied Biosystems 7500 Fast Real-Time PCR System. Analysis of ENaC $\alpha$ (Hs00168906_m1) and COX2 (Hs00153133_m1) was performed with TaqMan probe (Invitrogen Life Technologies). $18 \mathrm{~S}$ rRNA (catalog \#4319413E, Invitrogen Life Technologies) was used as internal control. Real-time PCR for mir-101 (ID-002253) and miR-199a-3p (ID-002304) was carried out with the microRNA Assay Kit (Invitrogen Life Technologies). SnoRNA202 (ID-001232, Invitrogen Life Technologies) was used as a control for mouse miRNAs and RNU48 (ID-001006, Invitrogen Life Technologies) was used as a control for human miRNAs.

\section{Statistical analysis}

The results are shown as mean \pm s.E.M. Student's unpaired $t$-test was used for two-group comparison. One-way ANOVA was used for comparing three or more groups. $P<0.05$ was considered as statistically significant.

\section{Results}

miR-101 and miR-199a-3p expression in mouse endometrial epithelial cells is dependent on ENaC in vitro and in vivo

To test if the expression of miR-101 and miR-199a-3p could possibly be subject to the change in $\mathrm{ENaC}$ function or expression in endometrial epithelial cells, we used previously established in vitro and in vivo mouse models in conjunction with the use of $\mathrm{ENaC}$ activator/inhibitor or siRNAs (Ruan et al. 2012). As shown in Fig. 1A, activation of $\mathrm{ENaC}$ by trypsin $(20 \mu \mathrm{g} / \mathrm{ml}, 15 \mathrm{~min})$ in primary cultures of mouse endometrial epithelial cells (mEECs) induced a 

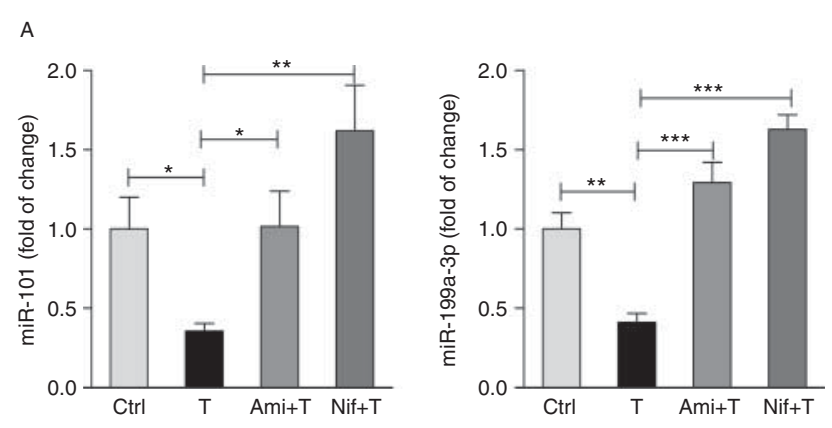

B
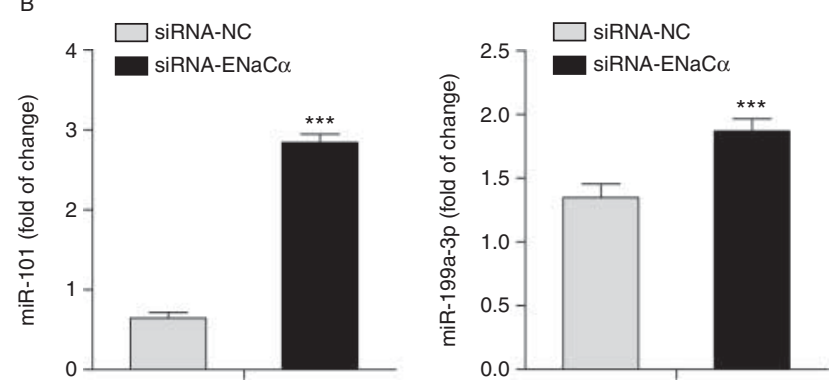

C
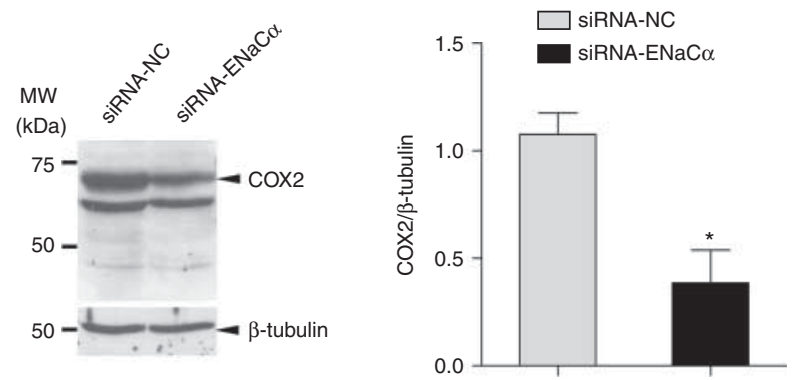

Figure $1 \mathrm{ENaC}$-dependent miR-101 and miR-199a-3p expression in mouse endometrial epithelial cell in vitro and in vivo. (A) Real-time PCR analysis of miR-101 and miR-199a in isolated mouse endometrial epithelial cells treated with ENaC activator, trypsin (T, $20 \mu \mathrm{g} / \mathrm{ml}), \mathrm{ENaC}$ blocker, amiloride (Ami, $10 \mu \mathrm{M})$, or L-type $\mathrm{Ca}^{2+}$ channel blocker, nifidipine (Nif, $10 \mu \mathrm{M}$ ). Ctrl, control cells. ${ }^{*} P<0.05 ;{ }^{*} P<0.01$ and *** $P<0.001, n=3$. One-way ANOVA. (B and C) Real-time PCR analysis of miR-101 and miR-199a-3p (B) and western blotting for COX2 (C) in mouse uteri $24 \mathrm{~h}$ after uterine injection of siRNAs-targeting $\mathrm{ENaC} \alpha$ (siRNA-ENaC $\alpha$ ) or siRNAs with a scrambled sequence as negative control (siRNA-NC). $\beta$-tubulin was used as a loading control. ${ }^{*} P<0.05$ and ${ }^{* * *} P<0.001, n=4, t$-test.

significant reduction in miR-101 and miR-199a-3p levels, which could be reversed by the pretreatment with amiloride $(10 \mu \mathrm{M}, 30 \mathrm{~min})$, an ENaC blocker, suggesting the involvement of $\mathrm{ENaC}$ in the regulation of these two miRNAs. Since we had shown previously that ENaC activation in $\mathrm{mEEC}$ resulted in $\mathrm{Ca}^{2+}$ influx through voltage-dependent $\mathrm{Ca}^{2+}$ channels, we also tested the effect of nifedipine, an inhibitor of L-type $\mathrm{Ca}^{2+}$ channel, on the expression of the two miRNAs. Indeed, similar to amiloride, pretreatment with nifedipine $(10 \mu \mathrm{M}$, $30 \mathrm{~min}$ ) also reversed the trypsin-induced decreases in miR-101 and miR-199a-3p expression levels (Fig. 1A), suggesting that these changes in miR-101 and miR-199a are subsequent to the $\mathrm{ENaC}$ activation-induced $\mathrm{Ca}^{2+}$ mobilization. Next, we determined whether ENaC could regulate these two miRNAs in vivo. We previously (Ruan et al. 2012) showed that intrauterine injection of siRNAs targeting $\mathrm{ENaC} \alpha$ subunit (siRNA-ENaC $\alpha$ ) in mice successfully knocked down uterine $\mathrm{ENaC} \alpha$ level at the implantation window (day 4 after mating), which resulted in a reduction in implantation rate in mice (Ruan et al. 2012). We used the same mouse implantation model in this study and found that when $\mathrm{ENaC}$ was knocked down, the expression levels of miR-101 and miR-199a-3p in the uteri were significantly increased as compared with that in the uteri injected with control siRNAs (siRNA-NC; Fig. 1B). More importantly, the increase in miR-101 and miR-199a3 p caused by $\mathrm{ENaC}$ knockdown was accompanied with a decrease in uterine COX2 protein level in siRNA-ENaC $\alpha$ treated mice compared with the control (Fig. 1C), further indicating the dependence of these two miRNAs and their target gene, Cox2, on $\mathrm{ENaC}$ during implantation.

\section{ENaC regulates COX2 through miR-101 and miR-199a-3p in human endometrial epithelial cells}

The observed role of $\mathrm{ENaC}$ in the regulation of the two miRNAs on mouse models prompted us to examine its role in the regulation of the miRNAs in a human endometrial surface epithelial cell line (HES). We first confirmed the expression of ENaC subunits $\alpha$ and $\gamma$ by western blotting analysis (Fig. 2A). ENaC knockdown was performed on HES cells by transducing lenti-virus (LV3) packaged shRNAs targeting to $\mathrm{ENaC} \alpha$ (shRNA-ENaC $\alpha$ ), with significant reduction in both mRNA and protein levels of ENaC $\alpha$ observed in HES cells (Fig. 2B). Similar to that observed in mouse models (Fig. 1), shRNA-EnaC $\alpha$ treated HES cells showed significant decreases in COX2 protein level (Fig. 2C) and $\mathrm{PGE}_{2}$ release (Fig. 2D), accompanied with increases in miR-101 and miR-199a$3 p$ expression levels (Fig. 2E), as compared with the control cells transduced with LV3-packaged shRNAs of scrambled sequence (shRNA-Ctrl). The reciprocal expression levels between COX2 and the two miRNAs in response to $\mathrm{ENaC}$ knockdown in both HES (Fig. 2C and E) and mouse models (Fig. $1 \mathrm{~B}$ and $\mathrm{C}$ ) suggest that the regulation of $\mathrm{COX} 2$ expression by $\mathrm{ENaC}$ may involve posttranscriptional modulation by these miRNAs. To prove this, we transfected specific inhibitors of miR-101 and miR-199a-3p individually to HES cells and the western blotting results (Fig. 2F) showed that the ENaCknockdown-induced reduction in COX2 protein level was significantly reversed by these inhibitors, indicating the involvement of these miRNAs in the modulation of the ENaC-regulated COX2 expression in HES cells.

\section{ENaC-dependent regulation of miRNAs involves CREB phosphorylation in HES cells}

We next examined the possible mechanism underlying the ENaC-dependent changes in the two miRNAs. 
A

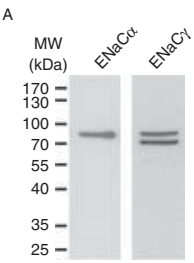

C
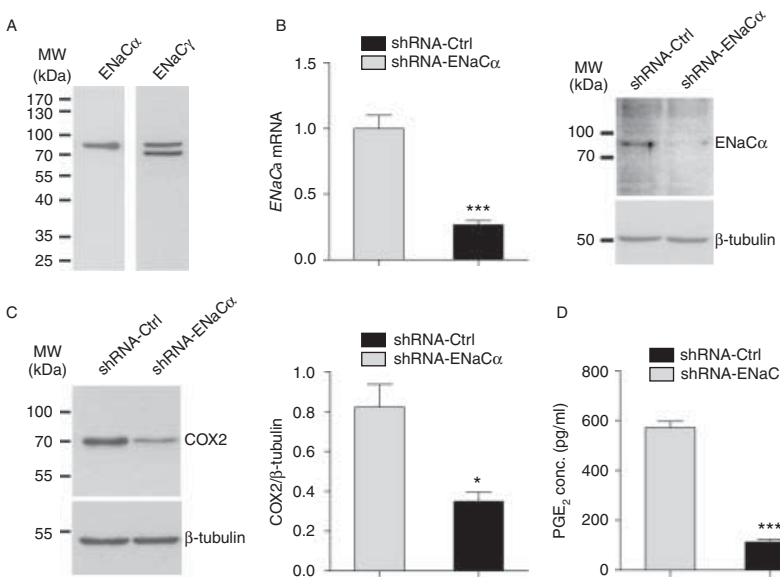

D

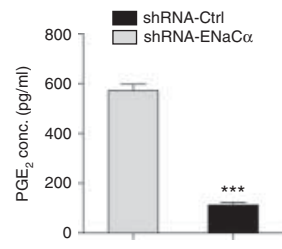

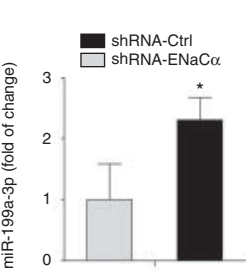
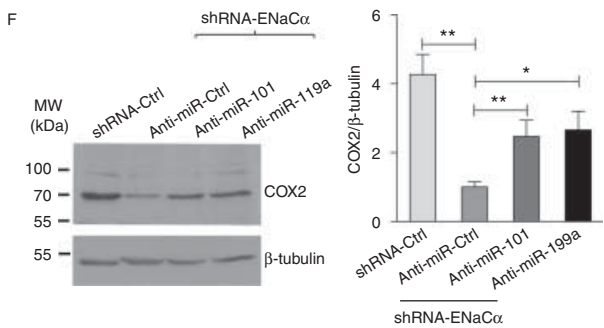

Figure 2 Involvement of miR-101 and miR-199a-3p in the modulation of ENaC-regulated COX2 expression in human endometrial epithelial (HES) cells. (A) Western blottings show $\mathrm{ENaC} \alpha$ and $\gamma$ subunits expression in HES cells. (B) Real-time PCR (left) and western blottings (right) show reduced ENaC mRNA and protein levels, respectively, after lenti-virus transduction with shRNA-targeting ENaC $\alpha(\operatorname{shRNA-ENaC} \alpha)$ or control shRNA (shRNA-Ctrl). (C and D) Western blotting for COX2 (C), ELISA for PGE $\mathrm{P}_{2}(\mathrm{D})$, and real-time PCR of miR-101 and miR-199a$3 p(E)$ in HES cells treated with shRNA-Ctrl or shRNA-ENaC $\alpha$. (F) COX2 protein levels in HES cells treated with shRNA-Ctrl, shRNA-ENaC $\alpha$ without or with the inhibitor of miR-101 (anti-miR-101) or miR-199a-3p (anti-miR-199a-3p), or the inhibitor control (anti-miR-Ctrl). $\beta$-tubulin was used as a loading control. ${ }^{*} P<0.05$; ${ }^{* *} P<0.01$; and ${ }^{* * *} P<0.001$, $n=3$, $t$-test

Since $\mathrm{ENaC}$ activation could lead to $\mathrm{Ca}^{2+}$ influx and CREB phosphorylation (Ruan et al. 2012) and CREB had also been implicated in repressing COX2-targeting miRNA (Kottakis et al. 2011), we tested the possible involvement of CREB phosphorylation in the regulation of the two COX2-targeting miRNAs. In HES cells, addition of trypsin $(20 \mu \mathrm{g} / \mathrm{ml})$ triggered intracellular $\mathrm{Ca}^{2+}$ increase, which was prevented by pretreatment with amiloride (10 $\mu \mathrm{M}, 30 \mathrm{~min})$, nifedipine $(1 \mu \mathrm{M}, 30 \mathrm{~min})$, or removal of extracellular $\mathrm{Ca}^{2+}$ (Fig. 3A). Also, trypsin $(20 \mu \mathrm{g} / \mathrm{ml})$ induced amiloride $(10 \mu \mathrm{M})$ - and nifedipine (10 $\mu \mathrm{M}$ )-sensitive CREB phosphorylation (Fig. 3B), COX2

up-regulation (Fig. 3C), and $\mathrm{PGE}_{2}$ release (Fig. 3D). At the same time, the trypsin treatment caused significant decreases in miR-101 and miR-199a-3p levels in HES cells (Fig. 3E), suggesting that activation of $\mathrm{ENaC}$ in HES cells can initiate a $\mathrm{Ca}^{2+} / \mathrm{CREB} / \mathrm{COX} 2$ signaling pathway leading to the miRNAs changes. To specifically test the role of $\mathrm{ENaC}$ in activation of CREB, we knocked down $\mathrm{ENaC} \alpha$ in HES cells, which caused significant reduction in phosphorylated CREB level (Fig. 3F), confirming that activation of $\mathrm{ENaC}$ promotes $\mathrm{CREB}$ activation in HES cells. As shown in Fig. 2E, ENaC $\alpha$ knockdown in HES cell also caused increases in miR-101 and miR-199a$3 p$. Thus, the results suggest that CREB may be involved in the transcription of these two miRNAs in response to the change in $\mathrm{ENaC}$ expression.

\section{miR-101/miR-199a-3p and COX2 expression levels in HES cells are dependent on CREB}

To further investigate the role of CREB in regulation of miR-101 and miR-199a-3p, we performed CREB knockdown in HES cells. siRNAs targeting to CREB (siRNACREB) were transfected into HES cells, which caused blockage of CREB protein expression in the cells in $48 \mathrm{~h}$ (Fig. 4A). The siRNA-CREB-transfected HES cells showed significant increases in miR-101 and miR199a-3p levels compared with the ones with control siRNAs (siRNA-NC). Meanwhile, the protein level of COX2 in siRNA-CREB treated cells was found decreased (Fig. 4C), which was partially reversed by transfection with miR-101 or miR-199a-3p inhibitors into HES cells (Fig. 4D). These results suggested an indirect role of CREB in regulation of COX2 through miR-101 and miR-199a-3p in HES cells.

\section{Knockdown of CREB results in the alteration of miR-101 and miR-199a-3p expression and implantation failure in mice}

We next tested whether the expression of miR-101 and miR-199a-3p may be affected by CREB during embryo implantation in vivo. To knockdown uterine CREB, siRNA-CREB was injected into uterine lumen in mice on day 3 , which resulted in a decrease in uterine CREB protein level on day 7 (Fig. 5A). The number of the implanted embryos in uteri injected with siRNA-CREB was found to be significantly less than the ones in the control uteri injected with siRNA-NC on day 7 (Fig. 5B). At the same time, the expression of miR-101 and miR199a-3p was significantly increased (Fig. 5C), and the COX2 protein level (Fig. 5D) decreased in the uteri treated with siRNA-CREB as compared with the controls.

\section{Discussion}

This study has demonstrated for the first time that $\mathrm{ENaC}$ activation in mouse and human endometrial epithelial 


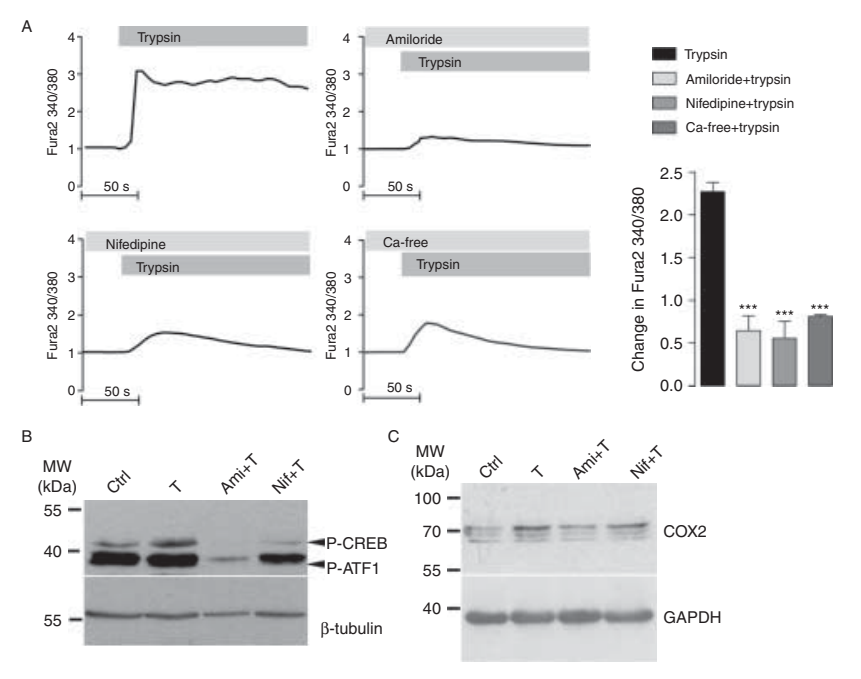

D
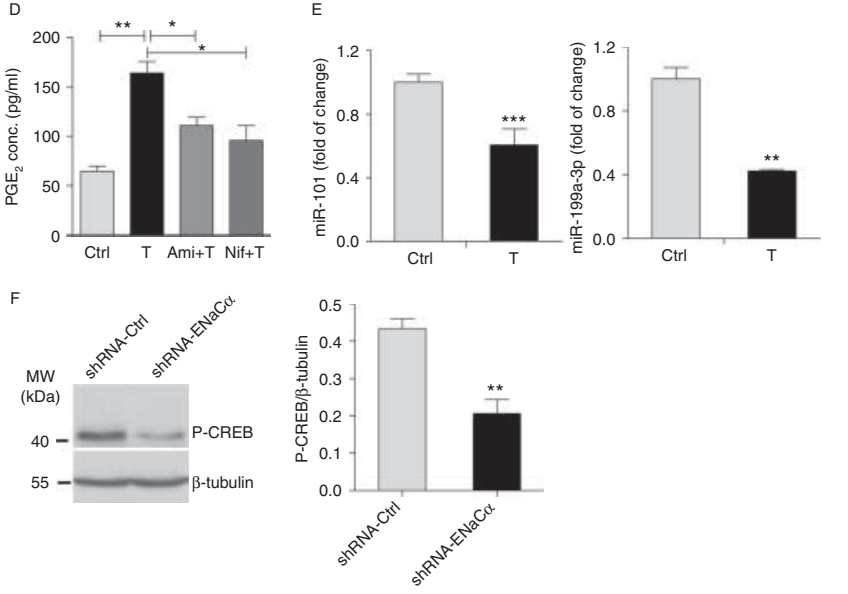

Figure 3 Involvement of $\mathrm{Ca}^{2+} / \mathrm{CREB}$ signaling in ENaC-dependent regulation of COX2-targeting miRNAs in HES cells. (A) Fura-2 measurements of intracellular $\mathrm{Ca}^{2+}$ changes in responses to trypsin $(\mathrm{T}, 20 \mu \mathrm{g} / \mathrm{ml})$, in the absence or presence of amiloride (Ami, $10 \mu \mathrm{M})$, nifedipine (Nif, $1 \mu \mathrm{M}$ ), or after removal of $\mathrm{Ca}^{2+}$ from the bath solution (Ca-free). ${ }^{* * *} P<0.001$ compared with the trypsin-treated group, $n=3-4$, one-way ANOVA. (B) Western blotting for phosphorylated CREB (P-CREB) in HES cells under different conditions. The antibody also recognizes phosphorylated ATF1. (C and D) COX2 expression (C) and $\mathrm{PGE}_{2}$ release (D) in HES cells under different conditions. Ctrl, control. Trypsin (T, $20 \mu \mathrm{g} / \mathrm{ml}$ ), amiloride (Ami, $10 \mu \mathrm{M}$ ), nifedipine (Nif, $10 \mu \mathrm{M})$. (E) Real-time PCR analysis of miR-101 and miR-199a-3p in HES cells treated with trypsin $(\mathrm{T}, 20 \mu \mathrm{g} / \mathrm{ml})$. (F) Western blotting for P-CREB in HES cells transfected with shRNA-Ctrl and shRNA-ENaC $\alpha$. $\beta$-tubulin was used as a loading control, $n=3,{ }^{*} P<0.05$ and ${ }^{* *} P<0.01$; $t$-test.

cells may lead to alteration in two COX2-targeting miRNAs through a CREB-dependent mechanism. The CREB-induced miR-101 and miR-199a-3p repression may contribute to the uterine COX2 upregulation in response to $\mathrm{ENaC}$ activation by embryo-derived protease, which may be important for successful embryo implantation.

Embryo implantation is a complex process involving a large network of genes (Cha et al. 2012, Koot et al. 2012). With their known capacity in the modulation of multiple genes expression, miRNAs have gained increasing attentions in the research into the molecular mechanisms underlying the process of embryo implantation. A number of miRNAs have been detected in the endometrium at the time of implantation in mice or at mid-secretory phase, the receptive window, in humans (Chakrabarty et al. 2007, Hu et al. 2008, Revel et al. 2011). Among these miRNAs, some are predicted or proved to target genes that are critical for embryo implantation, including COX2 (Chakrabarty et al. 2007), HOXA10 (Estella et al. 2012), LIF (Altmae et al. 2013), as well as WNT signaling (Revel et al. 2011, Altmae et al. 2013), p53 signaling components (Revel et al. 2011, Altmae et al. 2013). However, despite their recognized roles in embryo implantation, how the dynamic expression of miRNAs is controlled during implantation remains elusive. Although it has been reported that miRNAs are sensitive to environmental/extracellular cues, such as osmolality (Huebert et al. 2011), pH (Lu et al. 2012), and mechanical forces (Mohamed \& Boriek 2010, Qin et al. 2010), the exact mechanisms responsible for linking extracellular signals to changes in miRNAs are largely unexplored. Interestingly, as membrane proteins with signal transduction capacity, ion channels have been proposed to be candidate epigenetic regulators in linking extracellular signals to miRNA alterations in the cell (Jiang et al. 2012). Indeed, our recent study has demonstrated the important role of an anion channel, CFTR, in transducing the signal from extracellular bicarbonate into activation of miR-125b targeting p53 during embryo development (Lu et al. 2012). This study also provides strong evidence

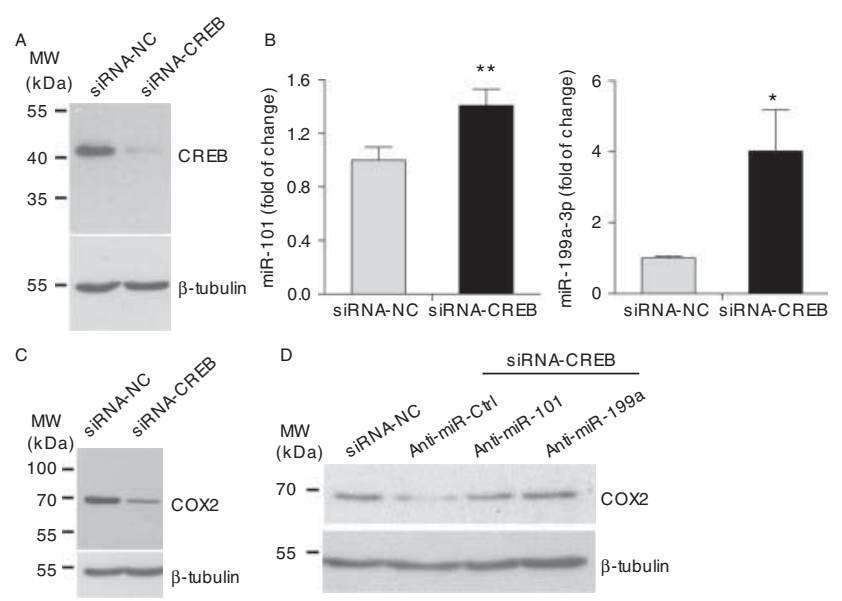

Figure 4 CREB-dependent miR-101 and miR-199a-3p expression in HES cells. (A) Western blottings show CREB levels in HES cells transfected with siRNA targeting to CREB (siRNA-CREB) or siRNAs with scrambled sequences as the negative control (siRNA-NC). (B and D) Real-time PCR analysis of miR-101 and miR-199a-3p (B) and western blotting for COX2 (C) in HES cells transfected with siRNA-CREB or siRNA-NC. (D) COX2 levels in HES cells transfected with siRNA-NC or siRNA-CREB without or with the inhibitor of miR-101 (anti-miR-101) or miR-199a-3p (anti-miR199a-3p), or the inhibitor control (anti-miR-Ctrl). $\beta$-tubulin was used as a loading control. $n=4,{ }^{*} P<0.05$ and ${ }^{* *} P<0.01 ; t$-test. 

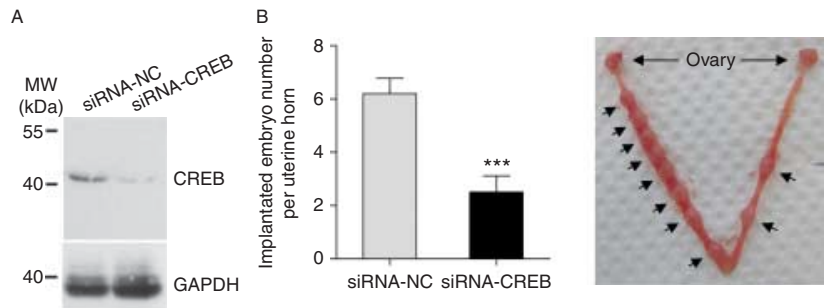

C
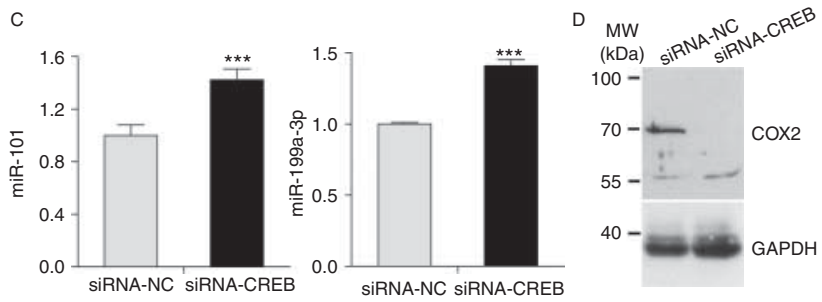

Figure 5 Effect of CREB knockdown on miR-101 and miR-199a-3p expression and embryo implantation in mice. (A) CREB levels in mouse uteri 4 days after the injection of siRNA-NC or siRNA-CREB. (B and D) Implanted embryo numbers (B), miR-101 and miR-199a-3p expression levels (C), and COX-2 protein levels (D) in mouse uteri on day 7 after the injection of siRNA-NC or siRNA-CREB. The photograph in (B) shows implantation sites (arrows) in the uterine horn injected with siRNA-NC (left) as compared with the one injected with siRNA-CREB (right). GAPDH was used as a loading control. The number of animals $(n)=10(\mathrm{~B})$ and $5(\mathrm{C}), * * * P<0.001, t$-test.

supporting an important role of ion channels, $\mathrm{ENaC}$ in this case, in the regulation of miRNAs. We have previously shown that COX2 transcription in mouse endometrial epithelial cells could be upregulated by activating $\mathrm{ENaC}$ and subsequently CREB in response to the embryo-derived protease, trypsin (Ruan et al. 2012). Whereas this is consistent with the well-documented direct role of CREB in the regulation of COX2 (Miller et al. 1998, Tsatsanis et al. 2006, Pham et al. 2008), a recent study has implicated CREB in the regulation of COX2-targeting miR-101a (Kottakis et al. 2011), suggesting possible additional mechanism involving miRNAs in mediating the effect of $\mathrm{ENaC}$ on COX2 upregulation during embryo implantation. Indeed, the results of the present study have clearly demonstrated the ability of ENaC to regulate the expression of COX2targeting miR-101 and miR-199a-3p in mouse and human endometrial epithelial cells through CREB phosphorylation. Inhibition or knockdown of ENaC resulted in increased expression of the two miRNAs with decreased expression level of COX2. Conversely, activation of $\mathrm{ENaC}$ by trypsin, a protease known to be released by implanting embryo (Sawada et al. 1990), produced opposite effects on the miRNAs and COX2, providing the first evidence that COX2-targeting miRNAs can be regulated by the embryo-derived factor through $\mathrm{ENaC}$. Taken together, these results suggest that miR-101 and miR-199a-3p are involved in the modulation of the expression of $\mathrm{COX} 2$ in response to $\mathrm{ENaC}$ activation during implantation. Interestingly, $\mathrm{ENaC}$ is also known to be activated by mechano-stimuli (Fronius \& Clauss 2008) and its expression in the endometrium is subject to alteration in ovarian hormones (Chan et al. 2002, Yang et al. 2004). Together with the demonstrated capacity of $\mathrm{ENaC}$ in the regulation of miRNAs, these suggest that $\mathrm{ENaC}$ might mediate other types of signals in regulation of miRNAs in different physiological contexts. For example, while $17 \beta$-estradiol $\left(E_{2}\right)$ is known to downregulate uterine $\mathrm{ENaC}$ in mice (Chan et al. 2002), it has also been reported to promote miR-199a expression in rat uterus (Xia et al. 2014). The promoting effect of $E_{2}$ on the miRNA might be mediated through its downregulating effect on $\mathrm{ENaC}$, given the present results showing the upregulation of miR-199a in response to inhibition or knockdown of $\mathrm{ENaC}$. As $\mathrm{ENaC}$ is expressed along the entire female reproductive tract, it would be interesting to explore whether $\mathrm{ENaC}$ may regulate other miRNAs

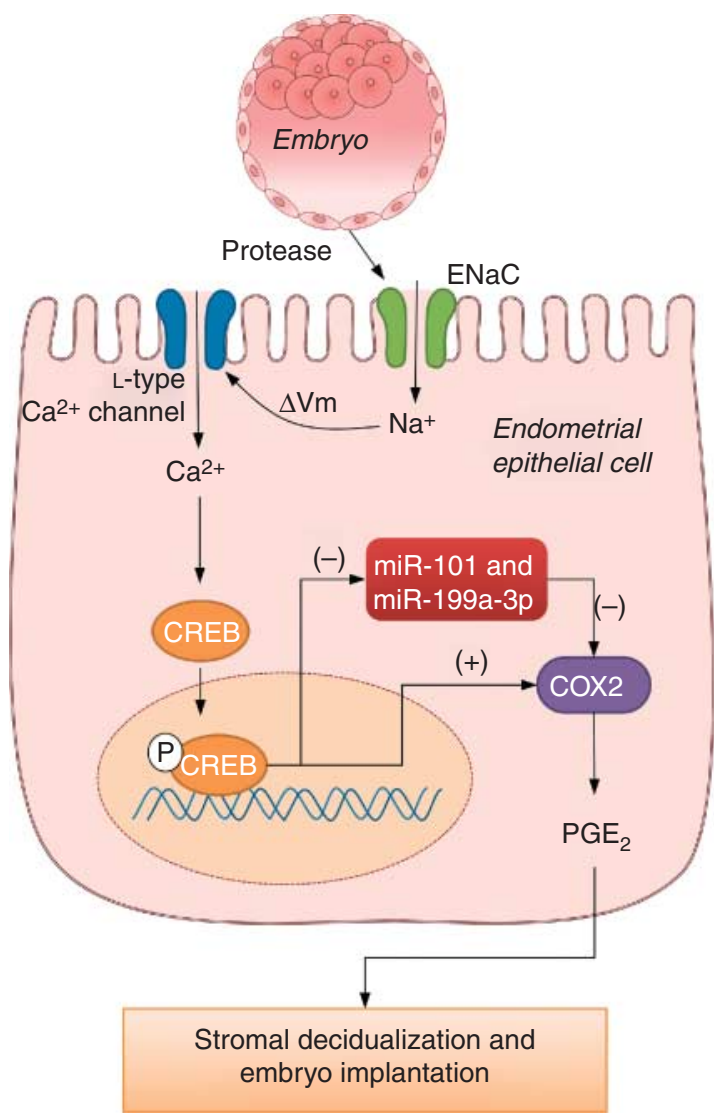

Figure 6 Working model for ENaC/CREB-dependent regulation of COX2 expression during embryo implantation. $\mathrm{ENaC}$ activation by serine proteases from the embryo causes epithelial cell membrane depolarization $(\Delta \mathrm{Vm})$ that in turn activates L-type $\mathrm{Ca}^{2+}$ channel with $\mathrm{Ca}^{2+}$ influx leading to phosphorylation of CREB, which can directly trigger the transcription of COX2 (Ruan et al. 2012). In addition, as demonstrated in this study, the ENaC-dependent CREB activation also suppresses miR-101 and miR-199-3p, which in turn post-transcriptionally upregulates COX2 in human endometrial epithelial cells. The ENaC/CREB-regulated COX2 upregulation leads to $\mathrm{PGE}_{2}$ production and release, which is essential for stromal decidualization and embryo implantation (Ruan et al. 2012). 
targeting different genes that are important for different processes of reproduction.

This study has also demonstrated a critical role of CREB in mediating the effect of $\mathrm{ENaC}$ in the regulation of the two COX2-targeting miRNAs. This is evident by the observation that knockdown of CREB in vitro or in vivo led to upregulation of miR-101 and miR-199a-3p expression levels, indicating an important role of CREB in repressing these two miRNAs. Interestingly, in a previous study, CREB has been demonstrated to drive the transcription of NDY1, which in turn suppresses miR-101a expression in mouse embryonic fibroblasts (Kottakis et al. 2011). Whether such a mechanism also underlies the presently observed regulatory action of CREB on miR-101 and miR-199a-3p in endometrial epithelial cells awaits further investigation. It should be noted that CREB is well known for its ability to bind directly to the promoter region of COX2 and transcriptionally potentiate COX2 (Miller et al. 1998, Tsatsanis et al. 2006, Pham et al. 2008). We have also shown previously that ENaC-dependent CREB activation promotes COX2 transcription in mouse endometrial epithelial cells (Ruan et al. 2012). The present observation that the decreases in COX2 protein levels induced by knockdown of CREB or ENaC can be partially reversed by inhibiting miR-101 or miR-199a-3p (Figs 2 and 4) indicates the involvement of the miRNAs in the modulation of the ENaC/CREB-induced upregulation of COX2. This also suggests that the ENaC-dependent CREB activation, which is subsequent to the $\mathrm{ENaC}$-induced membrane depolarization and $\mathrm{Ca}^{2+}$ mobilization (Ruan et al. 2012; Fig. 6) in endometrial epithelial cells, could possibly play a dual role, driving COX2 transcription directly on the one hand, and upregulating COX2 indirectly, on the other hand, through repressing the two miRNAs that post-transcriptionally modulate COX2 expression, as depicted in the working model (Fig. 6). Since COX2 is indispensable for normal implantation (Lim et al. 1997), the fine tuning of COX2 expression by ENaC/CREB-dependent miRNAs may be necessary for successful implantation. Of note, CREB has been reported to be activated in decidua cells (Kawarabayashi et al. 2012, Kusama et al. 2014) and implicated in preimplantation embryo development (O'Neill et al. 2012). This study has demonstrated, for the first time, a critical role of CREB in embryo implantation in vivo, as evidenced by the CREB knockdown-induced implantation failure observed in this study. However, further study is needed to assess the exact contribution of the two miRNAs in the process.

The study on embryo implantation in humans is difficult, particularly due to the ethical concerns and technical limitation upon humans, which is in fact precluding the advance in assistant reproductive technology. The present data obtained from human endometrial cells are consistent with those from mouse models, suggesting the relevance of ENaC-dependent regulation of miRNAs in human embryo implantation. The ability of $\mathrm{ENaC}$ to regulate COX2-targeting miRNAs, in addition to its previously demonstrated role in the regulation of $\mathrm{PGE}_{2}$ production and release during embryo implantation (Ruan et al. 2012), supports a critical and versatile role of $\mathrm{ENaC}$ in regulating the process of embryo implantation. Whereas previous study has demonstrated abnormally downregulated $\mathrm{ENaC}$ expression in women with implantation failure (Ruan et al. 2012), the currently demonstrated involvement of CREB and the miRNAs in the modulation of ENaC-regulated COX2 expression during embryo implantation suggests potential molecular targets, in addition to $\mathrm{ENaC}$, for diagnosis and treatment of implantation failure, which may also have applications for contraception.

\section{Declaration of interest}

The authors declare that there is no conflict of interest that could be perceived as prejudicing the impartiality of the research reported.

\section{Funding}

The work was supported in part by grants from the National Natural Science Foundation of China (81370709), National 973 project of China (2012CB944903), K.S. Lo Foundation, and the Focused Investment Scheme of the Chinese University of Hong Kong.

\section{Author contribution statement}

H C Chan conceived the study. H C Chan, H Chen, and Y C Ruan designed the experiments. X Sun, Y C Ruan, J Guo, $\mathrm{H}$ Chen, L L Tsang, and X Zhang performed the experiments and analyzed the data. $X$ Jiang provided intellectual input. X Sun, Y C Ruan, and H C Chan wrote the paper.

\section{References}

Achache H, Tsafrir A, Prus D, Reich R \& Revel A 2010 Defective endometrial prostaglandin synthesis identified in patients with repeated implantation failure undergoing in vitro fertilization. Fertility and Sterility 94 1271-1278. (doi:10.1016/j.fertnstert.2009.07.1668)

Akhtar N \& Haqqi TM 2012 MicroRNA-199a* regulates the expression of cyclooxygenase-2 in human chondrocytes. Annals of the Rheumatic Diseases 71 1073-1080. (doi:10.1136/annrheumdis-2011-200519)

Altmae S, Martinez-Conejero JA, Esteban FJ, Ruiz-Alonso M, StavreusEvers A, Horcajadas JA \& Salumets A 2013 MicroRNAs miR-30b, miR-30d, and miR-494 regulate human endometrial receptivity. Reproductive Sciences 20 308-317. (doi:10.1177/1933719112453507)

Cha J, Sun X \& Dey SK 2012 Mechanisms of implantation: strategies for successful pregnancy. Nature Medicine 18 1754-1767. (doi:10.1038/ nm.3012)

Chakrabarty A, Tranguch S, Daikoku T, Jensen K, Furneaux H \& Dey SK 2007 MicroRNA regulation of cyclooxygenase-2 during embryo implantation. PNAS $\mathbf{1 0 4}$ 15144-15149. (doi:10.1073/pnas. 0705917104) 
Chan LN, Wang XF, Tsang LL \& Chan HC 2000a Pyrimidinoceptorsmediated activation of $\mathrm{Ca}(2+)$-dependent $\mathrm{Cl}(-)$ conductance in mouse endometrial epithelial cells. Biochimica et Biophysica Acta 1497 261-270. (doi:10.1016/S0167-4889(00)00057-4)

Chan LN, Wang XF, Tsang LL, Liu CQ \& Chan HC $2000 \mathrm{~b}$ Suppression of CFTR-mediated $\mathrm{Cl}(-)$ secretion by enhanced expression of epithelial $\mathrm{Na}(+)$ channels in mouse endometrial epithelium. Biochemical and Biophysical Research Communications 276 40-44. (doi:10.1006/bbrc. 2000.3426)

Chan LN, Wang XF, Tsang LL, So SC, Chung YW, Liu CQ \& Chan HC 2001 Inhibition of amiloride-sensitive $\mathrm{Na}(+)$ absorption by activation of CFTR in mouse endometrial epithelium. Pflügers Archiv: European Journal of Physiology 443 (Suppl 1) S132-S136. (doi:10.1007/s004240100660)

Chan LN, Tsang LL, Rowlands DK, Rochelle LG, Boucher RC, Liu CQ \& Chan HC 2002 Distribution and regulation of ENaC subunit and CFTR mRNA expression in murine female reproductive tract. Journal of Membrane Biology 185 165-176. (doi:10.1007/s00232-001-0117-y)

Critchley HO, Jones RL, Lea RG, Drudy TA, Kelly RW, Williams AR \& Baird DT 1999 Role of inflammatory mediators in human endometrium during progesterone withdrawal and early pregnancy. Journal of Clinical Endocrinology and Metabolism 84 240-248. (doi:10.1210/jcem.84.1.5380)

Du T \& Zamore PD 2005 microPrimer: the biogenesis and function of microRNA. Development 132 4645-4652. (doi:10.1242/dev.02070)

Estella C, Herrer I, Moreno-Moya JM, Quinonero A, Martinez S, Pellicer A \& Simon C 2012 miRNA signature and Dicer requirement during human endometrial stromal decidualization in vitro. PLOS ONE 7 e41080. (doi:10.1371/journal.pone.0041080)

Fronius M \& Clauss WG 2008 Mechano-sensitivity of ENaC: may the (shear) force be with you. Pflügers Archiv: European Journal of Physiology 455 775-785. (doi:10.1007/s00424-007-0332-1)

He L \& Hannon GJ 2004 MicroRNAs: small RNAs with a big role in gene regulation. Nature Reviews. Genetics 5 522-531. (doi:10.1038/nrg1379)

Hossain MM, Salilew-Wondim D, Schellander K \& Tesfaye D 2012 The role of microRNAs in mammalian oocytes and embryos. Animal Reproduction Science 134 36-44. (doi:10.1016/j.anireprosci.2012.08.009)

Hu SJ, Ren G, Liu JL, Zhao ZA, Yu YS, Su RW, Ma XH, Ni H, Lei W \& Yang ZM 2008 MicroRNA expression and regulation in mouse uterus during embryo implantation. Journal of Biological Chemistry 283 23473-23484. (doi:10.1074/jbc.M800406200)

Huebert RC, Jagavelu K, Hendrickson HI, Vasdev MM, Arab JP, Splinter PL, Trussoni CE, Larusso NF \& Shah VH 2011 Aquaporin-1 promotes angiogenesis, fibrosis, and portal hypertension through mechanisms dependent on osmotically sensitive microRNAs. American Journal of Pathology 179 1851-1860. (doi:10.1016/j.ajpath.2011.06.045)

Hummler E, Barker P, Gatzy J, Beermann F, Verdumo C, Schmidt A, Boucher R \& Rossier BC 1996 Early death due to defective neonatal lung liquid clearance in $\alpha$-ENaC-deficient mice. Nature Genetics 12 325-328. (doi:10.1038/ng0396-325)

Jiang X, Zhang JT \& Chan HC 2012 lon channels/transporters as epigenetic regulators? - a microRNA perspective Science China. Life Sciences $\mathbf{5 5}$ 753-760. (doi:10.1007/s11427-012-4369-9)

Kawarabayashi Y, Hai L, Honda A, Horiuchi S, Tsujioka H, Ichikawa J \& Inoue R 2012 Critical role of TRPC1-mediated $\mathrm{Ca}(2)(+)$ entry in decidualization of human endometrial stromal cells. Molecular Endocrinology 26 846-858. (doi:10.1210/me.2011-1259)

Kniss DA, Zimmerman PD, Garver CL \& Fertel RH 1997 Interleukin-1 receptor antagonist blocks interleukin-1-induced expression of cyclooxygenase-2 in endometrium. American Journal of Obstetrics and Gynecology 177 559-567. (doi:10.1016/S0002-9378(97)70146-7)

Koot YE, Teklenburg G, Salker MS, Brosens JJ \& Macklon NS 2012 Molecular aspects of implantation failure. Biochimica et Biophysica Acta 1822 1943-1950. (doi:10.1016/j.bbadis.2012.05.017)

Kottakis F, Polytarchou C, Foltopoulou P, Sanidas I, Kampranis SC \& Tsichlis PN 2011 FGF-2 regulates cell proliferation, migration, and angiogenesis through an NDY1/KDM2B-miR-101-EZH2 pathway. Molecular Cell 43 285-298. (doi:10.1016/j.molcel.2011.06.020)

Kusama K, Yoshie M, Tamura K, Daikoku T, Takarada T \& Tachikawa E 2014 Possible roles of the cAMP-mediators Epac and Rap1 in decidualization of rat uterus. Reproduction 147 897-906. (doi:10.1530/REP-13-0654)

Li DK, Liu L \& Odouli R 2003 Exposure to non-steroidal anti-inflammatory drugs during pregnancy and risk of miscarriage: population based cohort study. BMJ 327 368. (doi:10.1136/bmj.327.7411.368)
Lim H, Paria BC, Das SK, Dinchuk JE, Langenbach R, Trzaskos JM \& Dey SK 1997 Multiple female reproductive failures in cyclooxygenase 2-deficient mice. Cell 91 197-208. (doi:10.1016/S0092-8674 (00)80402-X)

Lim H, Gupta RA, Ma WG, Paria BC, Moller DE, Morrow JD, DuBois RN, Trzaskos JM \& Dey SK 1999 Cyclo-oxygenase-2-derived prostacyclin mediates embryo implantation in the mouse via PPAR $\delta$. Genes and Development 13 1561-1574. (doi:10.1101/gad.13.12.1561)

Lu YC, Chen H, Fok KL, Tsang LL, Yu MK, Zhang XH, Chen J, Jiang X, Chung YW, Ma AC et al. 2012 CFTR mediates bicarbonate-dependent activation of miR-125b in preimplantation embryo development. Cell Research 22 1453-1466. (doi:10.1038/cr.2012.88)

Marions L \& Danielsson KG 1999 Expression of cyclo-oxygenase in human endometrium during the implantation period. Molecular Human Reproduction 5 961-965. (doi:10.1093/molehr/5.10.961)

Matsumoto H, Ma WG, Daikoku T, Zhao X, Paria BC, Das SK, Trzaskos JM \& Dey SK 2002 Cyclooxygenase-2 differentially directs uterine angiogenesis during implantation in mice. Journal of Biological Chemistry 277 29260-29267. (doi:10.1074/jbc.M203996200)

Miller C, Zhang M, He Y, Zhao J, Pelletier JP, Martel-Pelletier J \& Di Battista JA 1998 Transcriptional induction of cyclooxygenase-2 gene by okadaic acid inhibition of phosphatase activity in human chondrocytes: co-stimulation of AP-1 and CRE nuclear binding proteins. Journal of Cellular Biochemistry 69 392-413. (doi:10.1002/(SICI)1097-4644 (19980615)69:4<392::AID-JCB2 > 3.0.CO;2-I)

Mohamed JS \& Boriek AM 2010 Stretch augments TGF- $\beta 1$ expression through RhoA/ROCK1/2, PTK, and PI3K in airway smooth muscle cells. American Journal of Physiology. Lung Cellular and Molecular Physiology 299 L413-L424. (doi:10.1152/ajplung.90628.2008)

Nagaraja AK, Andreu-Vieyra C, Franco HL, Ma L, Chen R, Han DY, Zhu H, Agno JE, Gunaratne PH, DeMayo FJ et al. 2008 Deletion of Dicer in somatic cells of the female reproductive tract causes sterility. Molecular Endocrinology 22 2336-2352. (doi:10.1210/me.2008-0142)

Nilsen TW 2007 Mechanisms of microRNA-mediated gene regulation in animal cells. Trends in Genetics 23 243-249. (doi:10.1016/j.tig.2007. 02.011)

Norwitz ER, Schust DJ \& Fisher SJ 2001 Implantation and the survival of early pregnancy. New England Journal of Medicine 345 1400-1408. (doi:10.1056/NEJMra000763)

O'Neill C, Li Y \& Jin XL 2012 Survival signaling in the preimplantation embryo. Theriogenology 77 773-784. (doi:10.1016/j.theriogenology. 2011.12.016)

Ouellet DL, Perron MP, Gobeil LA, Plante P \& Provost P 2006 MicroRNAs in gene regulation: when the smallest governs it all. Journal of Biomedicine \& Biotechnology 2006 69616. (doi:10.1155//BB/2006/69616)

Pham H, Vincenti R \& Slice LW 2008 COX-2 promoter activation by AT1RGq-PAK-p38 $\beta$ signaling in intestinal epithelial cells. Biochimica et Biophysica Acta 1779 408-413. (doi:10.1016/j.bbagrm.2008.05.004)

Qin X, Wang X, Wang Y, Tang Z, Cui Q, Xi J, Li YS, Chien S \& Wang N 2010 MicroRNA-19a mediates the suppressive effect of laminar flow on cyclin D1 expression in human umbilical vein endothelial cells. PNAS 107 3240-3244. (doi:10.1073/pnas.0914882107)

Revel A, Achache H, Stevens J, Smith Y \& Reich R 2011 MicroRNAs are associated with human embryo implantation defects. Human Reproduction 26 2830-2840. (doi:10.1093/humrep/der255)

Ruan YC, Zhou W \& Chan HC 2011 Regulation of smooth muscle contraction by the epithelium: role of prostaglandins. Physiology $\mathbf{2 6}$ 156-170. (doi:10.1152/physiol.00036.2010)

Ruan YC, Guo JH, Liu X, Zhang R, Tsang LL, Dong JD, Chen H, Yu MK, Jiang X, Zhang XH et al. 2012 Activation of the epithelial $\mathrm{Na}^{+}$channel triggers prostaglandin $\mathrm{E}(2)$ release and production required for embryo implantation. Nature Medicine 18 1112-1117. (doi:10.1038/nm.2771)

Ruan YC, Chen H \& Chan HC 2014 lon channels in the endometrium: regulation of endometrial receptivity and embryo implantation. Human Reproduction Update 20 517-529. (doi:10.1093/humupd/dmu006)

Salker MS 2010 Role of epithelial sodium channels and their regulators in hypertension. Journal of Biological Chemistry 285 30363-30369. (doi:10.1074/jbc.R110.155341)

Sawada H, Yamazaki K \& Hoshi M 1990 Trypsin-like hatching protease from mouse embryos: evidence for the presence in culture medium and its enzymatic properties. Journal of Experimental Zoology 254 83-87. (doi:10.1002/jez.1402540112) 
Su L, Liu R, Cheng W, Zhu M, Li X, Zhao S \& Yu M 2014 Expression patterns of microRNAs in porcine endometrium and their potential roles in embryo implantation and placentation. PLOS ONE 9 e87867. (doi:10. 1371/journal.pone.0087867)

Tsang LL, Chan LN, Wang XF, So SC, Yuen JP, Fiscus RR \& Chan HC 2001 Enhanced epithelial $\mathrm{Na}(+)$ channel $(\mathrm{ENaC})$ activity in mouse endometrial epithelium by upregulation of $\gamma \mathrm{ENaC}$ subunit. Japanese Journal of Physiology 51 539-543. (doi:10.2170/jjphysiol.51.539)

Tsatsanis C, Androulidaki A, Venihaki M \& Margioris AN 2006 Signalling networks regulating cyclooxygenase-2. International Journal of Biochemistry \& Cell Biology 38 1654-1661. (doi:10.1016/j.biocel.2006.03.021)

Wilcox AJ, Weinberg CR, O'Connor JF, Baird DD, Schlatterer JP, Canfield RE, Armstrong EG \& Nisula BC 1988 Incidence of early loss of pregnancy. New England Journal of Medicine 319 189-194. (doi:10.1056/NEJM198807283190401)
Xia HF, Cao JL, Jin XH \& Ma X 2014 MiR199a is implicated in embryo implantation by regulating Grb10 in rat. Reproduction 147 91-99. (doi:10.1530/REP-13-0290)

Yang JZ, Ajonuma LC, Tsang LL, Lam SY, Rowlands DK, Ho LS, Zhou CX, Chung YW \& Chan HC 2004 Differential expression and localization of CFTR and $\mathrm{ENaC}$ in mouse endometrium during pre-implantation. Cell Biology International 28 433-439. (doi:10.1016/j.cellbi. 2004.03.011)

Received 31 July 2014

First decision 21 August 2014

Revised manuscript received 25 August 2014

Accepted 2 September 2014 